\title{
Fique Fiber Tensile Elastic Modulus Dependence with Diameter Using the Weibull Statistical Analysis
}

\author{
Maria Carolina Andrade Teles ${ }^{a}$, Giulio Rodrigues Altoé ${ }^{a}$, Pedro Amoy Netto ${ }^{a}, H_{e n r y}$ Colorado ${ }^{b}$ \\ Frederico Muylaert Margem ${ }^{a}$, Sergio Neves Monteiro ${ }^{c *}$

\begin{abstract}
${ }^{a}$ Laboratório de Materiais Avançados - LAMAV, Universidade Estadual do Norte Fluminense Darcy Ribeiro - UENF, Av. Alberto Lamego, 2000, CEP 28013-602, Campos dos Goytacazes, RJ, Brazil

${ }^{b}$ Cements, Ceramics, \& Composites Laboratory, Universidad de Antioquia - UdeA, Calle 70, no. 52-21, Medellin, Colombia

${ }^{c}$ Departamento de Ciência dos Materiais, Instituto Militar de Engenharia - IME, Praça General Tibúrcio, 80, Praia Vermelha, CEP 22290-270, Urca, Rio de Janeiro, RJ, Brazil
\end{abstract}

Received: December 10, 2014; Revised: May 1, 2015

\begin{abstract}
Fique is a plant native of Colombia with fibers extracted from its leaves presenting relevant physical characteristics and mechanical properties for possible engineering applications, such as reinforcement of polymer composites. The main physico-mechanical properties of the fique fiber have already been investigated for both untreated and mechanically treated fibers. The statistical distribution of the fique fiber diameter was analyzed and the effect of microfibrillar angle on the tensile strength and elongation was determined. However, the correlation of mechanical properties with the fiber diameter is yet to be determined. Thus, the present work evaluated the tensile elastic modulus dependence of the fique fiber as a function of its diameter. By means of the Weibull statistical analysis, it was found that an inverse correlation adjusted the elastic modulus with the equivalent diameter through a hyperbolic type of mathematical relationship. Similar correlation have been found for several lignocellulosic fibers not only by the research group of the present work but also other international groups The results are compared and discussed.
\end{abstract}

Keywords: fique fiber, elastic modulus, weibull analysis, hyperbolic equation

\section{Introduction}

Since the past two decades, a marked increase is taking place in research works and engineering applications of lignocellulosic fibers obtained from both naturally occurring and cultivated plants. In less than 20 years, more than one thousand scientific papers have been published on the characteristics and properties of hundreds of different fibers and distinct sub-species. These figures are certainly increasing owing not only to the potential of plants with promising fibers but also to the possibility of replacing synthetic fibers in terms of environmental, economical, societal and technical advantages ${ }^{1}$. One should not be surprised by this remarkable potential if it is accepted that only wood encompasses around 10,000 distinct species. In principle, for each lignocellulosic species of plant, fibers with distinct properties from different parts, such as leaves, stem, fruits, and even roots could be extracted for engineering purposes ${ }^{1}$.

Today, one of the motivations for investigating lignocellulosic fibers is the possible substitution for synthetic fiber in polymer composites. Indeed, since the beginning in World War II, synthetic fiber composites have successfully been applied in many areas of our modern civilization from medical devices to aerospace components. Today, in particular, the energy, pollution, cost and health problems of the glass fiber

*e-mail: snevesmonteiro@gmail.com are motivating its replacement by lignocellulosic fibers ${ }^{2-4}$. Several review articles have discussed the advantages and drawbacks of the most important lignocellulosic fibers and related polymer composites ${ }^{5-17}$. Furthermore, specific publications were dedicated to already existing applications of lignocellulosic fiber composites in industrial sectors, from construction panels and doors ${ }^{18}$ to automobile parts manufacturing ${ }^{19-21}$.

Among the less known lignocellulosic fibers that were not included in the aforementioned review articles, the fique fiber, Figure 1, deserves special attention for its relevant properties. The fique plant (Furcraea andina), illustrated in Figure 1a, is native of Colombia and its production has expanded to Ecuador, Costa Rica, Antilles and Brazil ${ }^{22}$. Fibers extracted from the stiff leaves of the fique bush, Figure 1b, are also known in some regions of Colombia as cabuya. The extraction is performed by mechanical technique and, for polymer composite reinforcement, the fique fiber may be used untreated or chemically treated according to the type of matrix employed ${ }^{23}$. As indicated by Gañan and Mondragon ${ }^{22}$, the fique fibers are relatively lighter, $0.87 \mathrm{~g} / \mathrm{cm}^{3}$, and can withstand temperatures up to $220^{\circ} \mathrm{C}$. They reported tensile strength of $237 \pm 51 \mathrm{MPa}$, elastic modulus of $8.01 \pm 1.47 \mathrm{GPa}$ and total elongation of $6.02 \pm 0.69 \%$. A diameter dispersion of the untreated fique fiber was shown by Gañan and Mondragon ${ }^{22}$ to extend from 0.06 to $0.26 \mathrm{~mm}$. 


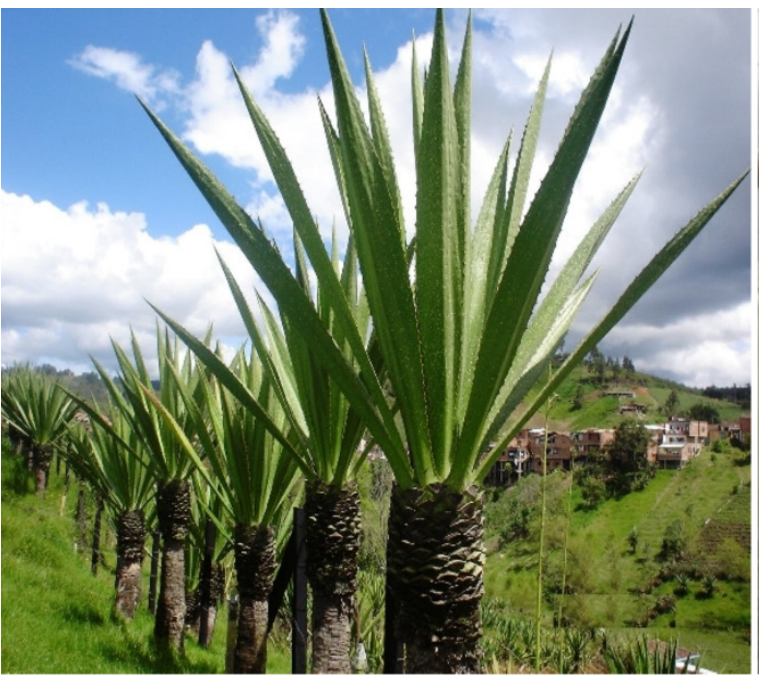

(a)

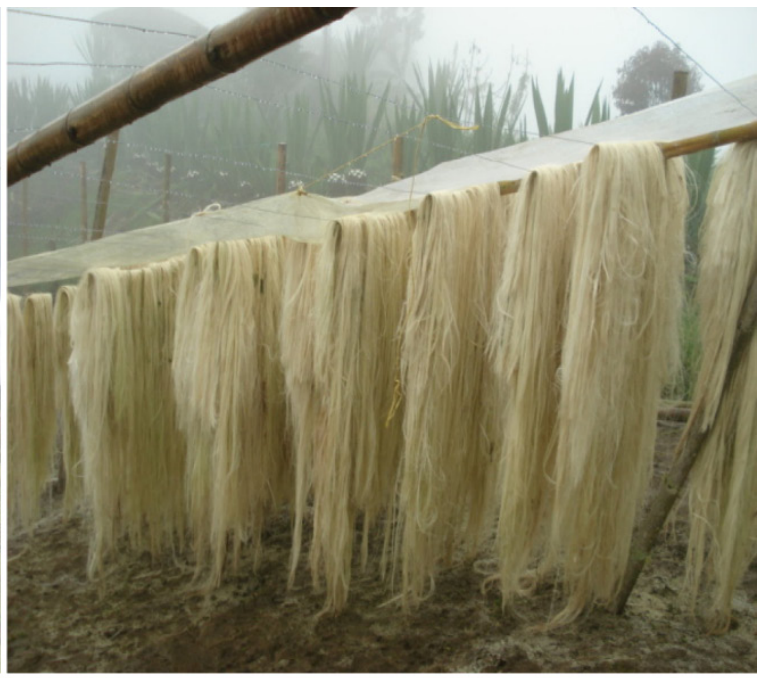

(b)

Figure 1. The fique (Furcraea andina): (a) cultivated plants and (b) extracted fiber drying in open air. Source: authors.

However, no correlation was indicated by the authors to exist between the mechanical properties and the diameter.

Investigation on changes in mechanical properties as a function of lignocellulosic fiber diameter has been reported since more than four decades ${ }^{24-30}$. Earlier international research groups investigated $\operatorname{coir}^{24}$, banana ${ }^{25}$, sisal $^{26}$, pineapple ${ }^{27}$, palmyrah and talipot ${ }^{28}$ fibers. In these earlier works no correlation was proposed for the variation of mechanical properties with fiber diameter. More recently ${ }^{29-36}$ it was found for several lignocellulosic fibers that both tensile strength and elastic modulus decrease as the fiber diameter increases. In particular, Biagiotti et al. ${ }^{31}$ were the first to indicate a mathematical expression using the Griffith model:

$\tau$ or $\mathrm{E}=\mathrm{A}+\mathrm{B} / \mathrm{d}$

where $\mathrm{d}$ is the fiber diameter, $\tau$ is the tensile strength, $\mathrm{E}$ the elastic modulus, $\mathrm{A}$ and $\mathrm{B}$ distinct constants for the different properties and fibers.

In a previous overview ${ }^{1}$ by the research group of the present work, it was also reported an inverse correlation between the diameter (d) and the tensile strength of several well known lignocellulosic fibers. Additionally, inverse diameter correlations were also recently found for the density ${ }^{37-42}$ and the elastic modulus ${ }^{37,40,43-45}$. Using the Weibull analysis in all these properties - strength $(\sigma)$, density $(\rho)$ and elastic modulus (E) - a simple hyperbolic type of mathematical adjustment was always obtained, similar to Equation 1.

In the particular case of the fique fiber, a more recent publication ${ }^{46}$ indicated that an inverse hyperbolic correlation also exists between the tensile strength and the diameter. From this inverse correlation, mathematical hyperbolic equations for both the Weibull characteristic strength, $\theta$, and the average strength, $\bar{\sigma}$, were found as:

$\theta=19.5 / \mathrm{d}+13.8$

$\bar{\sigma}=17.1 / d+15.2$

In order to complement the data associated with the mechanical properties, the objective of the present work was to evaluate the fique fiber tensile elastic modulus dependence with corresponding diameter using the Weibull statistical analysis.

\section{Experimental Procedure}

The basic material used in this work was the fiber extracted from the leaf of fique plant (Furcraea andina). A bundle of fique fibers was supplied by one of the co-authors, Henry Colorado, who obtained it from a producer in Colombia. The fibers were extracted by retting followed by scrapping from leaves collected in 2014. The as-supplied fique fibers were cleaned and dried in a stove at $60^{\circ} \mathrm{C}$ for 24 hours. From 100 fibers randomly selected from the bundle, each corresponding equivalent diameter was directly measured in a model 6C Nikon profile projector. The equivalent diameter was obtained, following procedures indicated in several works ${ }^{1,24-28}$, as an average between the larger and smaller $\left(90^{\circ}\right.$ rotation) cross section dimensions at five locations along the fiber's length. By considering the fiber with irregular cross-section (distinct dimensions in $90^{\circ}$ rotation), the average measurements were associated with the fiber equivalent diameter. Taking into account the distribution of diameters, from the smallest to the largest, seven conventional intervals divided the range.

The histogram in Figure 2 displays the frequency of equivalent diameter distribution for the seven conventional intervals established in the present work. The fique fiber diameters varied from 0.09 to $0.30 \mathrm{~mm}$ with a mean proportional value of $18.12 \mathrm{~mm}$. For each interval of equivalent diameter in Figure 2, 20 fibers were selected. All fibers with $10 \mathrm{~cm}$ of length were individually tensile tested at a temperature of $25 \pm 2{ }^{\circ} \mathrm{C}$ in a model 5582 universal Instron machine operating under a strain rate of $2 \times 10^{-4} \mathrm{~s}^{-1}$. Especial tensile grips were used to avoid both slippage and damage of the fiber. The values obtained for the elastic modulus, associated with the slope of the initial part of the stress-strain curve, were interpreted by means of the Weibull statistics using the computer program Weibull Analysis. 
The Weibull statistical analysis is based on a cumulative distribution function:

$\mathrm{F}(\mathrm{x})=1-\exp \left[-(\mathrm{x} / \theta)^{\beta}\right]$

where $\theta$ and $\beta$ are mathematically known as the shape and scale parameters. Equation 4 can be conveniently modified into a linear expression by double application of logarithm:

$\ln \ln \left(\frac{1}{1-\mathrm{F}(\mathrm{x})}\right)=\beta \ln \mathrm{x}-(\beta \ln \theta)$

In the present case of fique fiber elastic modulus dependence with diameter, $\beta$ is the slope, Equation 5, and indicated as the Weibull modulus, while $\theta$ is the characteristic elastic modulus. Using the 20 experimental strength data for each interval in Figure 2, associated with an average equivalent diameter, the computer program constructed the linear graph of Equation 5 and calculated the Weibull parameters.

The microstructural aspects of the fique fiber with different diameters and the corresponding rupture characteristics were examined by scanning electron microscopy (SEM) in a model SSX-550 Shimadzu microscope. The SEM fiber samples were gold sputtered and observed with secondary electrons at $15 \mathrm{kV}$.

\section{Results and Discussion}

Figure 3 depicts typical load versus elongation curves of fique fibers for each of the seven equivalent diameter intervals in Figure 2. Based on the maximum load (L), the tensile strength $\left(\sigma_{\mathrm{m}}\right)$ was determined for each fiber as

$\sigma_{\mathrm{m}}=4 \mathrm{~L} / \pi \mathrm{d}^{2}$

where $\mathrm{d}$ is the equivalent diameter in Figure 2.

Using the stress-strain slope in the initial elastic regimen, the elastic modulus (E) was calculated for each tensile tested fique fiber. The average value of $\bar{E}$ was statistically determined by means of the Weibull method for the 20 fibers associated with each of the seven diameter intervals shown in the histogram of Figure 2. The Weibull Analysis program provided the probability graphs of Equation 5 for the values of $\bar{E}$ that are shown in Figure 4 for all diameter intervals. Here it should be noted that all plots in Figure 4 are unimodal, i.e. with just

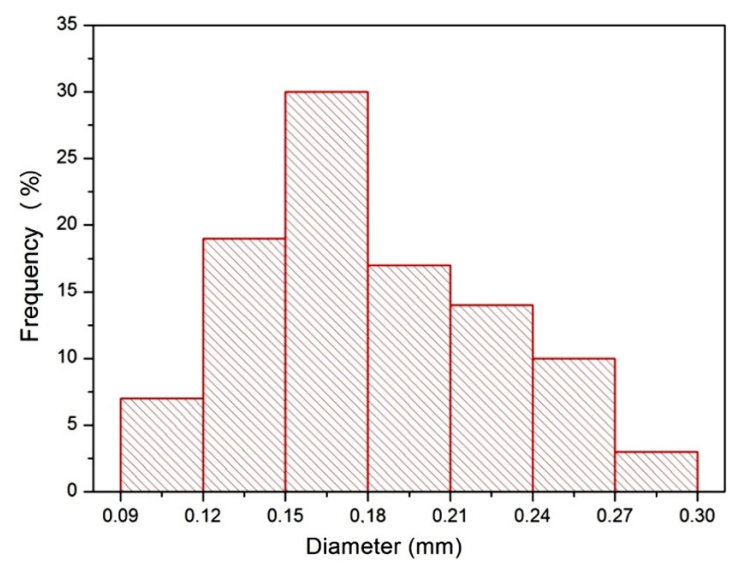

Figure 2. Histogram of the frequency of equivalent fique fiber diameter for the seven conventionally established intervals. Source: authors. one single straight line fitting the points at each interval. This indicates similar stiffness behavior of fibers within the same diameter interval.

In addition, the Weibull program also provided the corresponding characteristic elastic modulus $(\theta)$, the Weibull modulus $(\beta)$ and the precision adjustment $\left(\mathrm{R}^{2}\right)$ parameters. The values of these parameters as well as the mean elastic modulus $\left(\mathrm{E}_{\mathrm{m}}\right)$ and associated statistical deviations, based on the Weibull distribution, are presented in Table 1.

The variation of the characteristic elastic modulus with the average fiber diameter for each one of its intervals is shown in Figure 5. In this figure, there is a clear tendency for the $\theta$ parameter to vary inversely with the average fique fiber diameter. This indicates that the thinner the fiber the higher tends to be the characteristic elastic modulus. Furthermore, the corresponding values of $\beta$ and $\mathrm{R}^{2}$, shown in Table 1 , statistically support the inverse correlation between $\theta$ and the equivalent diameter $\mathbf{d}(\mathrm{mm})$. By means of a mathematic correlation, a hyperbolic type of equation is proposed to fit the data in Figure 5.

$\theta(\mathrm{GPa})=19.5 / \mathrm{d}+13.8$

In order to analyze the physical meaning of Equation 7 , the Weibull mean elastic modulus, $\mathrm{E}_{\mathrm{m}}$, evaluated in this work for the fique fibers was plotted as a function of the
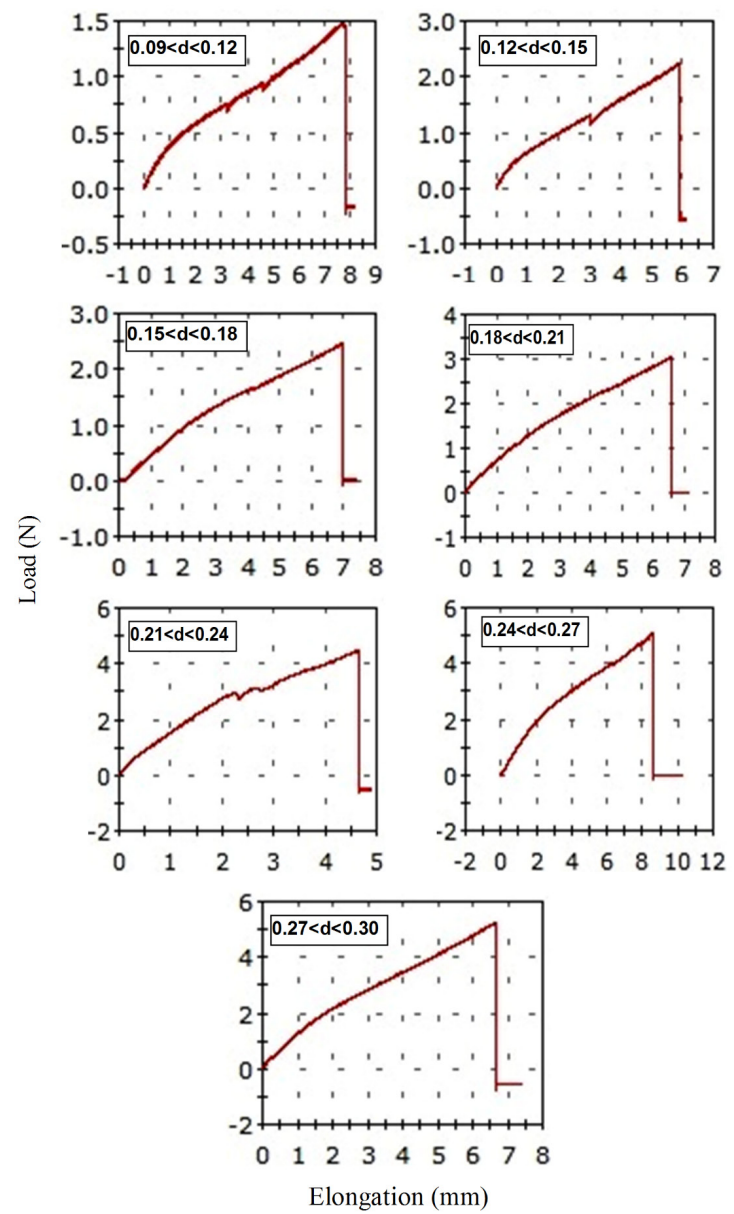

Figure 3. Typical load versus elongation curves of tensile tested fique fibers for each equivalent diameter interval. Source: authors. 
diameter in Figure 6. In this figure, an apparent hyperbolic inverse correlation also exists between $\mathbf{E}_{\mathbf{m}}$ and $\mathbf{d}$ within the error bars (statistical deviations) and investigated limits. In spite of a higher dispersion in the error bars, a tendency for hyperbolic inverse correlation also exists between $\mathrm{E}_{\mathrm{m}}$ and $\mathbf{d}$.
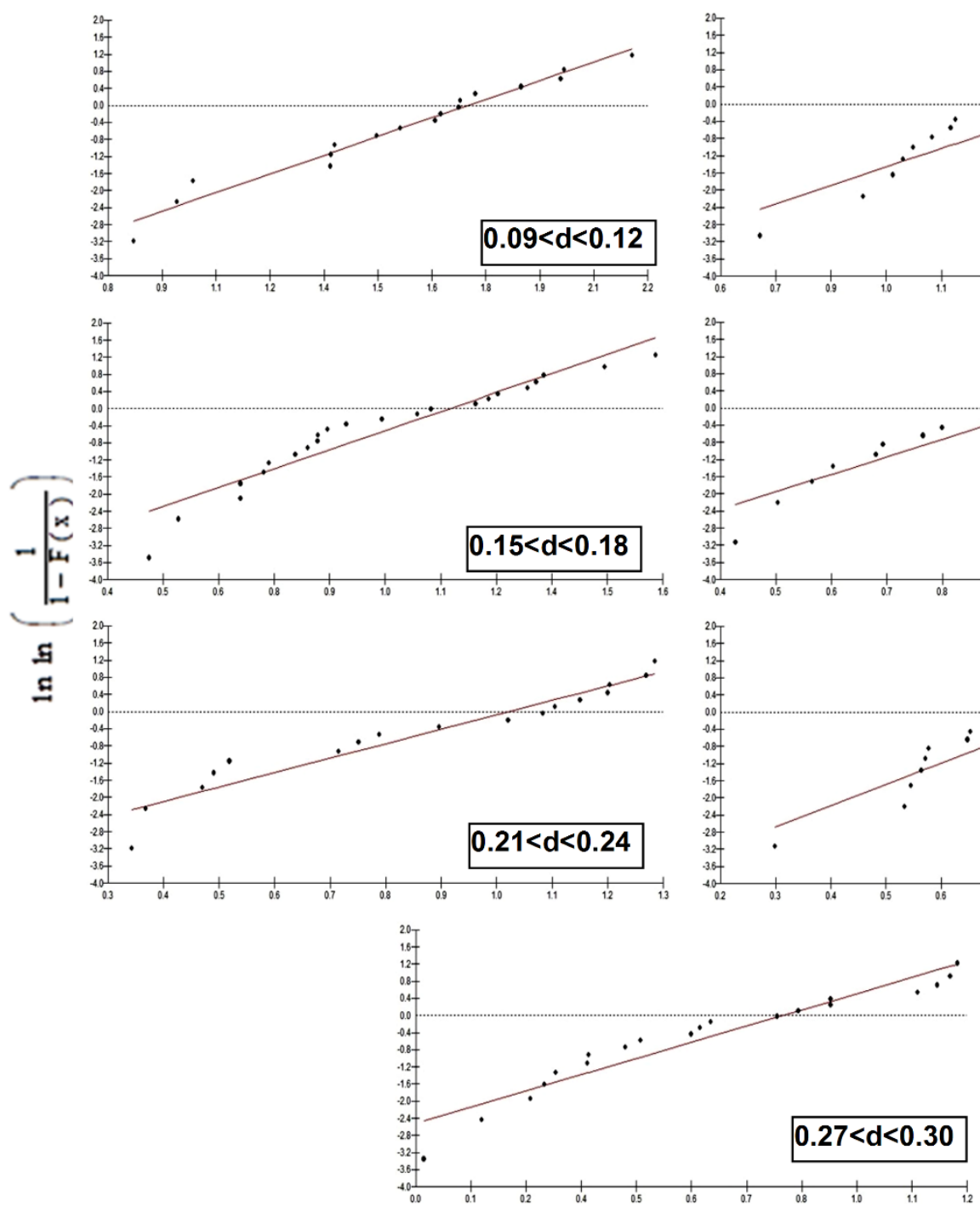

$\ln \mathrm{x}$
$\mathrm{E}_{\mathrm{m}}(\mathrm{GPa})=17.1 / \mathrm{d}+15.2$

Based on the similarity between Equation 7 and 8 it is suggested that, as in other lignocellulosic fibers ${ }^{34-37,40,43-45}$, a hyperbolic type of mathematical equation is a simple and reliable statistical correlation between the elastic modulus
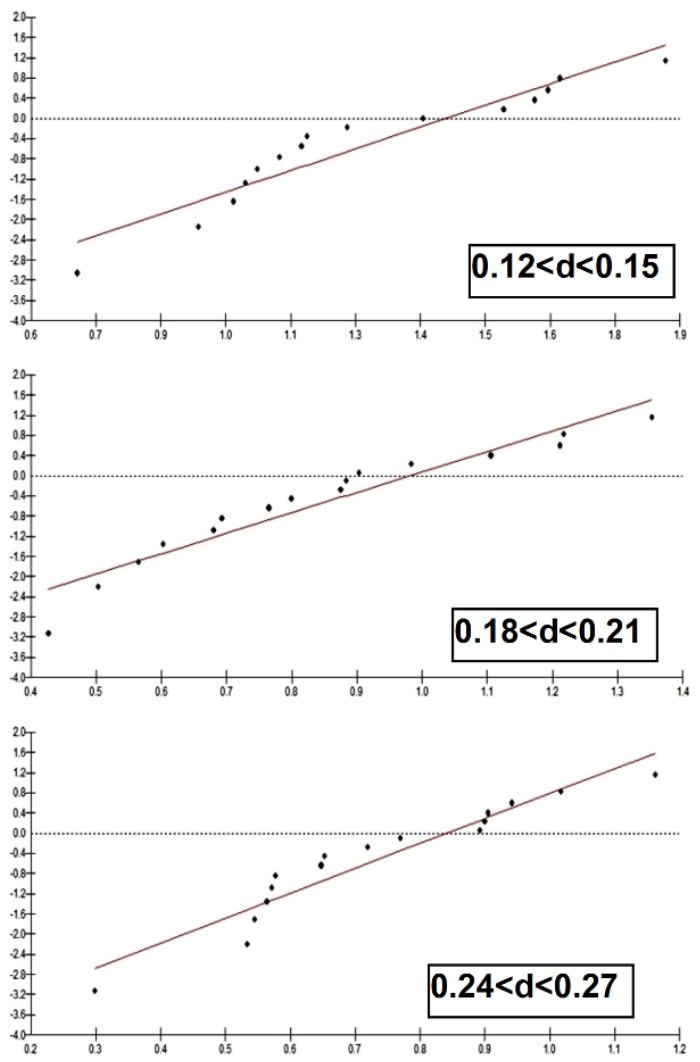

\section{$0.27<d<0.30$}

Figure 4. Weibull graphs of the elastic modulus reliability function for each equivalent diameter interval. Source: authors.

Table 1. Weibull parameters for the average elastic modulus of fique fibers associated with different diameter intervals.

\begin{tabular}{cccccc}
\hline $\begin{array}{c}\text { Diameter interval } \\
(\mathbf{m m})\end{array}$ & $\begin{array}{c}\text { Weibull Modulus, } \\
\boldsymbol{\beta}\end{array}$ & $\begin{array}{c}\text { Characteristic } \\
\text { Elastic Modulus, } \\
\boldsymbol{\theta}(\mathbf{G P a})\end{array}$ & $\begin{array}{c}\text { Precision } \\
\text { Adjustment } \mathbf{R}^{2}\end{array}$ & $\begin{array}{c}\text { Average Elastic } \\
\text { Modulus } \\
(\mathbf{G P a})\end{array}$ & $\begin{array}{c}\text { Statistical } \\
\text { Deviation }\end{array}$ \\
\hline $0.09-0.12$ & 3.137 & 5.659 & 0.9676 & 5.06 & 1.768 \\
$0.12-0.15$ & 3.303 & 4.191 & 0.9026 & 3.76 & 1.253 \\
$0.15-0.18$ & 3.705 & 3.123 & 0.9082 & 2.82 & 0.847 \\
$0.18-0.21$ & 4.064 & 2.667 & 0.9151 & 2.42 & 0.669 \\
$0.21-0.24$ & 3.369 & 2.78 & 0.9244 & 2.50 & 0.818 \\
$0.24-0.27$ & 4.935 & 2.32 & 0.9126 & 2.13 & 0.493 \\
$0.27-0.30$ & 3.15 & 2.22 & 0.9183 & 1.99 & 0.692 \\
\hline
\end{tabular}




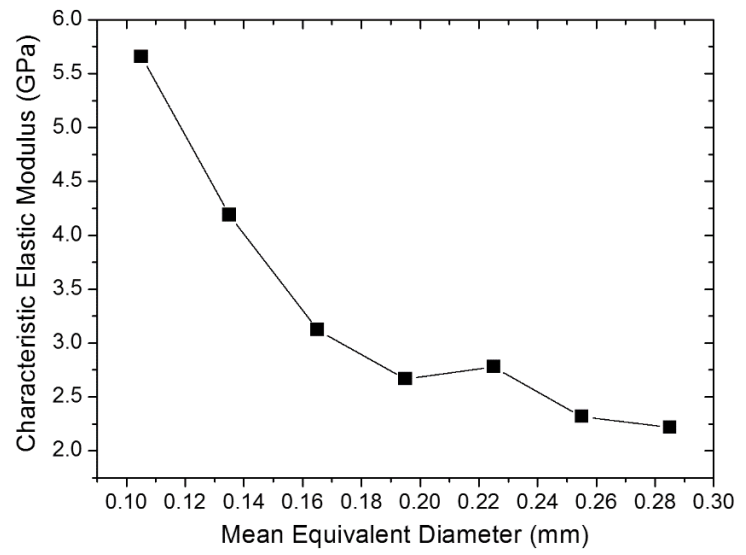

Figure 5. Variation of the Weibull characteristic elastic modulus with the mean equivalent diameter for each interval in Figure 3. Source: authors.

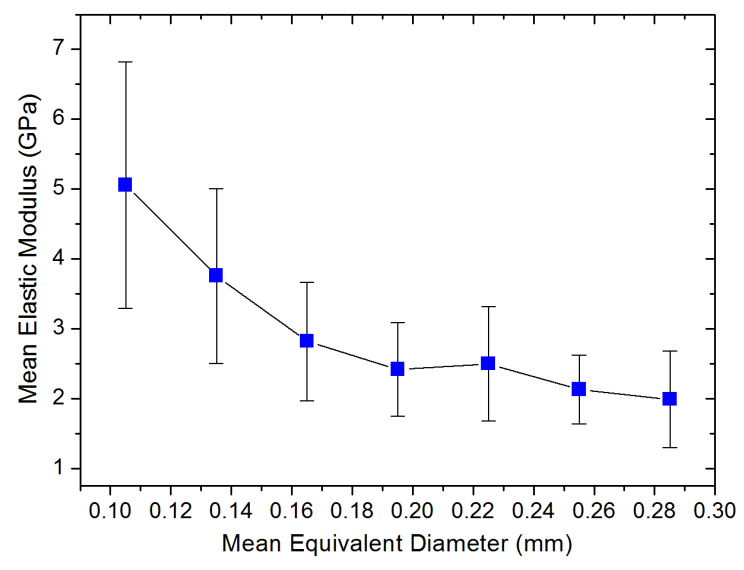

Figure 6. Variation of the Weibull average elastic modulus with the mean equivalent diameter for each interval in Figure 3. Source: authors.

and the diameter of fique fibers. In practice, this indicates that thinner fique fibers are stiffer than thicker ones. A reason for the stiffness inverse correlation with diameter may be attributes to both microstructural aspects and random rupture of microfibrils.

Figure 7 reveals by SEM micrographs the aspects of fique fibers, both thinner and thicker. As shown in Figure 7a, the thinner fique fiber with $\mathrm{d}=0.10 \mathrm{~mm}$ possesses a more homogenous microstructure, in which microfibrils rupture occurs simultaneously, arrow in Figure $7 \mathrm{~b}$. On the other hand, the thicker fiber, with $d=0.20 \mathrm{~mm}$ in Figure $7 \mathrm{c}$ has more flaws and voids (arrows) associated with a non-uniform rupture of microfibrils, as indicated by arrow in Figure $7 \mathrm{~d}$. Apparently, the more homogenous thinner fiber has fewer points for crack nucleation with more close packed microfibrils. This contributes to fiber cross-section and surface with less defects and voids and, consequently, a more resisting area associated with higher elastic modulus. Another reason for the inverse correlation could be the random distribution of greater number of microfibrils in the thicker fique fiber, Figure $7 \mathrm{c}$ and $\mathrm{d}$. The statistical chance is that, with more fibers, one microfibril in the thicker fiber will be weaker than those in the thinner fiber. Rupture will then start earlier in the thicker fiber, resulting in lower stiffness.

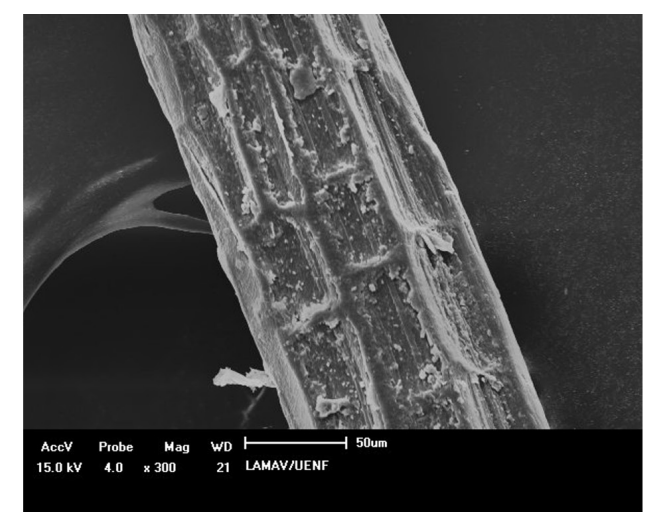

(a)

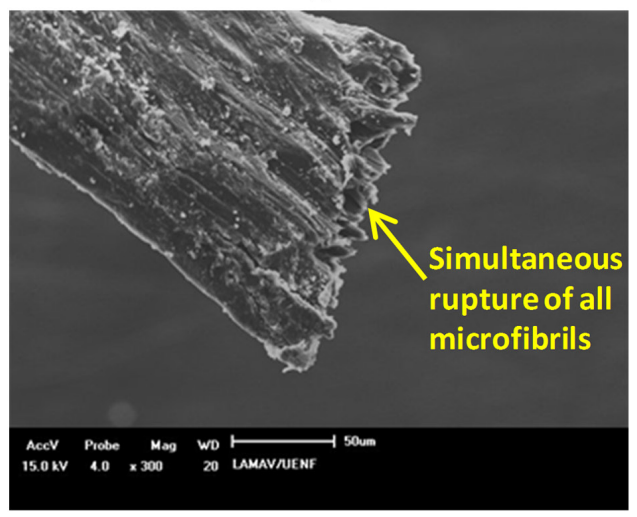

(b)

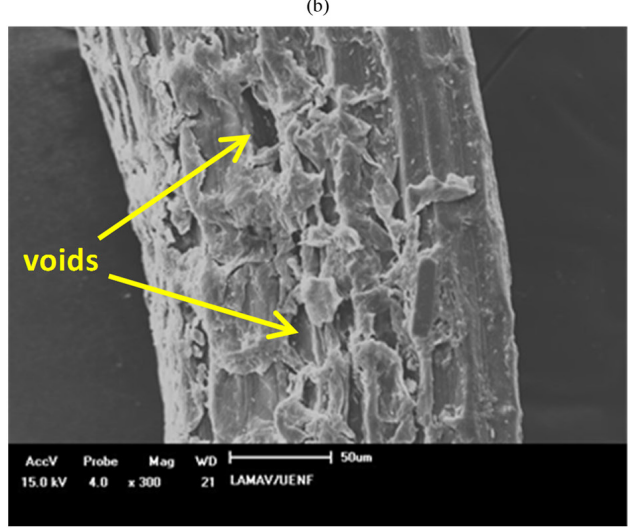

(c)

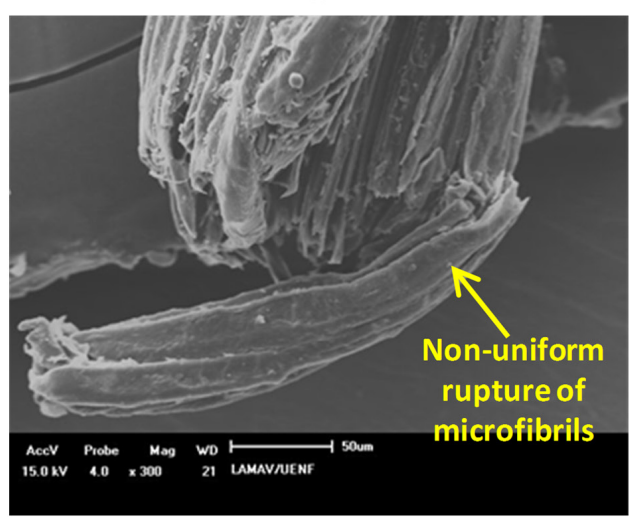

(d)

Figure 7. SEM micrographs for: (a) and (b) thinner fiber as well as (c) and (d) thicker fiber. Source: authors. 


\section{Conclusions}

- A Weibull statistical analysis of the elastic modulus of fique fibers found an inverse correlation with the fiber corresponding equivalent diameter. This correlation of the type $\mathrm{E}=\mathrm{A}+\mathrm{B} / \mathrm{d}$, also obtained for many other fibers, indicates a very close hyperbolic mathematical fit for both the Weibull characteristic elastic modulus $(\theta)$ and the mean elastic modulus $\left(\mathrm{E}_{\mathrm{m}}\right)$, as found by several international research groups since 2004 .

- SEM micrographs revealed evidences that thicker fique fibers possess more flaws and voids than the thinner ones. This heterogeneous behavior associated

\section{References}

1. Monteiro SN, Lopes FPD, Barbosa AP, Bevitori AB, Silva ILA and Costa LL. Natural lignocellulosic fibers as engineering materials - an overview. Metallurgical and Materials Transactions. A, Physical Metallurgy and Materials Science. 2011; 42(10):2963-2974. http://dx.doi.org/10.1007/s11661011-0789-6.

2. Corbière-Nicollier T, Gfeller Laban B, Lundquist L, Leterrier Y, Månson J-A and Jolliet O. Life cycle assessment of biofibres replacing glass fibres as reinforcement in plastics. Resources, Conservation and Recycling. 2001; 33(4):267-287. http://dx.doi. org/10.1016/S0921-3449(01)00089-1.

3. Wambua P, Ivens I and Verpoest I. Natural fibers: can they replace glass and fibre reinforced plastics? Composites Science and Technology. 2003; 63(9):1259-1264. http://dx.doi.org/10.1016/ S0266-3538(03)00096-4.

4. Joshi SV, Drzal LT, Mohanty AK and Arora S. Are natural fiber composites environmentally superior to glass fiber reinforced composites? Composites Part A: Applied Science and Manufacturing. 2004; 35(3):371-376. http://dx.doi.org/10.1016/j. compositesa.2003.09.016.

5. Satyanarayana KG, Sukunaran K, Mukherjee PS, Pavithran $\mathrm{C}$ and Pillai SGK. Natural fibre-polymer composites. Cement and Concrete Composites. 1990; 12(2):117-136. http://dx.doi. org/10.1016/0958-9465(90)90049-4.

6. Bledzki AK and Gassan J. Composites reinforced with cellulosebased fibers. Progress in Polymer Science. 1999; 24(2):221-274. http://dx.doi.org/10.1016/S0079-6700(98)00018-5.

7. Nabi Saheb D and Jog JP. Natural fiber polymer composites: a review. Advances in Polymer Technology. 1999; 18(4):351-363. http://dx.doi.org/10.1002/(SICI)1098-2329(199924)18:4<351::AIDADV6>3.0.CO;2-X.

8. Mohanty AK, Misra M and Hinrichsen G. Biofibers, biodegradable polymers and biocomposites: an overview. Macromolecular Materials and Engineering. 2000; 276-277(1):1-24. http:// dx.doi.org/10.1002/(SICI)1439-2054(20000301)276:1<1::AIDMAME1>3.0.CO;2-W.

9. Eichhorn SJ, Baillie CA, Zafeiropoulos N, Mwakambo LY, Ansell MP, Dufresne A, et al. Review: current international research into cellulosic fibres and composites. Journal of Materials Science. 2001; 36(9):2107-2131. http://dx.doi. org/10.1023/A:1017512029696.

10. Mohanty AK, Misra M and Drzal LT. Sustainable bio-composites from renewable resources: opportunities and challenges in the green materials world. Journal of Polymers and the Environment. 2002; 10(1-2):19-26. http://dx.doi.org/10.1023/A:1021013921916. with defects results in comparatively lower stiffness for the thicker fibers.

- Statistically, the greater number of microfibrils of the thicker fiber might also be expected to cause earlier rupture of the weaker microfibril, due to its random chance of belonging to the thicker fiber. This contributed to a higher stiffness of the thinner fiber as well.

\section{Acknowledgements}

The authors thank the support to this investigation by the Brazilian agencies: CNPq, CAPES and FAPERJ.

11. Netravali AN and Chabba S. Composites get greener. Materials Today. 2003; 6(4):22-29. http://dx.doi.org/10.1016/S13697021(03)00427-9.

12. Crocker J. Natural materials. Materials Technology. 2008; 23(3):174-178. http://dx.doi.org/10.1179/175355508X373378.

13. John MJ and Thomas S. Biofibers and biocomposites. Carbohydrate Polymers. 2008; 71(3):343-364. http://dx.doi. org/10.1016/j.carbpol.2007.05.040.

14. Satyanarayana KG, Arizaga GGC and Wypych F. Biodegradable composites based on lignocellulosic fibers - an overview. Progress in Polymer Science. 2009; 34(9):982-1021. http:// dx.doi.org/10.1016/j.progpolymsci.2008.12.002 .

15. Monteiro SN, Lopes FPD, Ferreira AS and Nascimento DCO. Natural fiber polymer matrix composites: cheaper, tougher and environmentally friendly. JOM. 2009; 61(1):17-22. http:// dx.doi.org/10.1007/s11837-009-0004-z.

16. Faruk O, Bledzki AK, Fink HP and Sain M. Biocomposites reinforced with natural fibers. Progress in Polymer Science. 2012; 37(11):1552-1596. http://dx.doi.org/10.1016/j. progpolymsci.2012.04.003.

17. Thakur VK, Thakur MK and Gupta RK. Review: raw natural fibers based polymer composites. International Journal of Polymer Analysis and Characterization. 2014; 19(3):256-271. http://dx.doi.org/10.1080/1023666X.2014.880016.

18. Thomas S, Paul SA, Pothan LA and Deepa B. Natural fibers: structure, properties and applications. In: Kalia S, Kaith BS and Kaurs I, editors. Bio-and nano-polymer composites. Berlin: Springer-Verlag; 2011. p 3-42.

19. Marsh G. Next step for automotive materials. Materials Today. 2003; 6(4):36-43. http://dx.doi.org/10.1016/S13697021(03)00429-2.

20. Holbery $\mathrm{J}$ and Houston D. Natural fiber reinforced polymer composites in automotive applications. JOM. 2006; 58(11):8086. http://dx.doi.org/10.1007/s11837-006-0234-2.

21. Zah R, Hischier R, Leão AL and Brown I. Curaua fibers in automobile industry - a sustainability assessment. Journal of Cleaner Production. 2007; 15(11-12):1032-1040. http://dx.doi. org/10.1016/j.jclepro.2006.05.036.

22. Gañán P and Mondragon I. Surface modification of fique fibers. Effects of their phisico-mechanical properties. Polymer Composites. 2002; 23(3):383-394. http://dx.doi.org/10.1002/ pc. 10440.

23. Gañán P and Mondragon I. Thermal and degradation behavior of fique fiber reinforced thermoplastic matrix composites. Journal of Thermal Analysis and Calorimetry. 2003; 73(3):783-795. http://dx.doi.org/10.1023/A:1025830430267. 
24. Kulkarni AG, Satyanarayana KG, Sukumaran K and Rohatgi PK. Mechanical behavior of coir fibers under tensile load. Journal of Materials Science. 1981; 16(4):905-914. http:// dx.doi.org/10.1007/BF00542734.

25. Kulkarni AG, Satyanarayana KG, Rohatgi PK and Vijayan K. Mechanical properties of banana fibers (Musa sapientum). Journal of Materials Science. 1983; 18(8):2290-2296. http:// dx.doi.org/10.1007/BF00541832.

26. Mukherjee PS and Satyanarayana KG. Structure and properties of some vegetables fibers. Part 1 - sisal fibers. Journal of Materials Science. 1984; 19(12):3925-3934. http://dx.doi. org/10.1007/BF00980755.

27. Mukherjee PS and Satyanarayana KG. Structure and properties of some vegetables fibers. Part 2 - pineapple fibers. Journal of Materials Science. 1986; 21(1):51-56. http://dx.doi.org/10.1007/ BF01144698.

28. Mukherjee PS and Satyanarayana KG. Structure and properties of some vegetables fibers. Part 3 - talipot and palmyrah fibers. Journal of Materials Science. 1986; 21(1)51-56. http://dx.doi. org/10.1007/BF01144698.

29. Baley C. Analysis of the flax fibres tensile behaviour and analysis of the tensile stiffness increase. Composites. Part A, Applied Science and Manufacturing. 2002; 33(7):939-948. http://dx.doi.org/10.1016/S1359-835X(02)00040-4.

30. Shibata M, Takachiyo K-I, Ozawa K, Yosomiya R and Takeishi H. Biodegradable polyester composites reinforced with short abaca fiber. Journal of Applied Polymer Science. 2002; 85(1):129-138. http://dx.doi.org/10.1002/app.10665.

31. Biagiotti J, Fiori S, Torre L, López-Manchado MA and Kenny JM. Mechanical properties of polypropylene matrix composites reinforced with natural fibers: a statistical approach. Polymer Composites. 2004; 25(1):26-36. http://dx.doi.org/10.1002/ pc.20002.

32. Andersons J, Sparninš E, Joffe R and Wallström L. Strength distribution of elementary flax fibres. Composites Science and Technology. 2005; 65(3-4):693-702. http://dx.doi.org/10.1016/j. compscitech.2004.10.001.

33. Park J-M, Quang ST, Hwang B-S and DeVries KL. Interfacial evaluation of modified Jute and Hemp fibers/polypropylene (PP)-maleic anhydride polypropylene copolymers (PPMAPP) composites using micromechanical technique and nondestructive acoustic emission. Composites Science and Technology. 2006; 66(15):2686-2699. http://dx.doi.org/10.1016/j. compscitech.2006.03.014.

34. Peponi L, Biagiotti J, Torre L, Kenny JM and Mondragón I. Statistical analysis of the mechanical properties of natural fibers and their composite materials I. Natural fibers. Polymer Composites. 2008; 29(3):313-320. http://dx.doi.org/10.1002/ pc. 20408 .

35. De Rosa IM, Kenny JM, Puglia D, Santulli C and Sarasini F. Morphological, thermal and mechanical characterization of okra (Abelmoschus esculentus) fibers as potential reinforcement in polymer composites. Composites Science and Technology. 2010; 70(1):116-122. http://dx.doi.org/10.1016/j.compscitech.2009.09.013.

36. Fiore V, Valenza A and Di Bella G. Artichoke (Cynara cardunculus L.) fibres as potential reinforcement composite structures. Composites Science and Technology. 2011; 71(8):1138-1144. http://dx.doi.org/10.1016/j.compscitech.2011.04.003.
37. Simonassi NT, Loiola RL, Carreiro RS, Margem FM and Monteiro SN. Weibull analysis of the density and elastic modulus of curaua fiber with different diameters. In: Proceedings of the 67th Annual Congress of the Brazilian Association of Metallurgy and Materials; 2012; Rio de Janeiro, Brazil. Rio de Janeiro; 2012.

38. Margem JI, Simonassi NT, Margem FM and Monteiro SN. Weibull analysis of the density of malva fibers with different diameters. In: Proceedings of the 67th Annual Congress of the Brazilian Association of Metallurgy and Materials; 2012; Rio de Janeiro, Brazil. Rio de Janeiro; 2012.

39. Barbosa AP, Oliveira MP, Crespo AS, Santos NSS, Margem FM and Monteiro SN. Correlation between the density and the diameter of buriti fibers. In: Hwang J-Y, Monteiro SN, Bai C, Carpenter JS, Cai M, Firrao D, et al. editors. Characterization of Minerals, Metals \& Materials 2012. Hoboken: John Wiley \& Sons; 2012. p. 365-371.

40. Pereira AC, Inacio WP, Margem FM and Monteiro SN. Effect of the fiber equivalent diameter on the elastic modulus and density of sisal fibers. In: Hwang J-Y, Monteiro SN, Bai C, Carpenter JS, Cai M, Firrao D, et al., editors. Characterization of Minerals, Metals \& Materials 2012. Hoboken: John Wiley \& Sons; 2012. p. 357-364.

41. Bevitori AB, Silva ILA, Oliveira CG, Margem FM and Monteiro SN. Weibull analysis of the density of ramie fibers with different diameters. In: Carpenter JS, Bai C, Hwang J-Y, Ikhmayies S, Li B, Monteiro SN, et al., editors. Characterization of Minerals, Metals \& Materials 2014. Hoboken: John Wiley \& Sons; 2014. p. 515-522.

42. Monteiro SN, Margem FM, Santafé HPG Jr, Martins LBS and Oliveira MP. Correlation between the diameter and the density of coir fiber using the Weibull statistical methodology. Materials Science Forum. 2014; 775-776:266-271. http://dx.doi. org/10.4028/www.scientific.net/MSF.775-776.266.

43. Oliveira MP, Barbosa AP, Silva VB, Margem FM and Monteiro SN. Weibull analysis of the elastic modulus of buriti fibers with different diameters. In: Proceedings of the 67th Annual Congress of the Brazilian Association of Metallurgy and Materials; 2012; Rio de Janeiro, Brazil. Rio de Janeiro; 2012.

44. Bevitori AB, Silva ILA, Carreiro RS, Margem FM and Monteiro $\mathrm{SN}$. Elastic modulus variation with diameter for ramie fibers. In: Hwang J-Y, Monteiro SN, Bai C, Carpenter JS, Cai M, Firrao D, et al., editors. Characterization of Minerals, Metals \& Materials 2012. Hoboken: John Wiley \& Sons; 2012. p. 395-402.

45. Martins LBS, Monteiro SN, Margem FM, Loiola RL, Pereira AC and Margem JI. Weibull analysis of the elastic modulus of bamboo fiber of the species Dendrocalmus giganteous. In: Hwang J-Y, Bai C, Carpenter JS, Ikhmayies S, Li B, Monteiro SN, et al., editors. Characterization of Minerals, Metals \& Materials 2013, Hoboken: John Wiley \& Sons; 2013. p. 441 448.

46. Altoé GR, Puglia AL, Margem FM and Monteiro SN. Weibull analysis of the tensile strength of fique fibers. In: Pan American Materials Conference; 2014; São Paulo, Brazil. São Paulo; 2014. 